\title{
CARACTERIZAÇÃO FÍSICO-QUÍMICA DA FARINHA DA FOLHA DE CENOURA (Daucus carota) E A APLICAÇÃO NA ELABORAÇÃO DE PRODUTOS ALIMENTÍCIOS
}

\section{PHYSICOCHEMICAL CHARACTERIZATION OF THE FLOUR LEAVE CARROT (Daucus carota) AND APPLICATION IN PREPARATION OF FOOD PRODUCTS}

\author{
Odenel Moreira Castilho Júnior ${ }^{1}$, Adriana Paiva de Oliveira ${ }^{2}$ \\ ${ }^{1}$ Universidade de Cuiabá - UNIC - Cuiabá - Brasil odeneljunior@ hotmail.com \\ ${ }^{2}$ Instituto Federal de Educação, Ciência e Tecnologia de Mato Grosso - Campus Cuiabá - Bela Vista - \\ IFMT - Cuiabá - Brasil dri_poliv@ig.com.br
}

\begin{abstract}
Resumo
Este trabalho tem como objetivo a determinação de parâmetros físico-químicos em farinha das folhas de cenoura (Daucus carota) e a elaboração de um biscoito a base desta farinha. A caracterização físico-química foi feita por meio da determinação da composição centesimal, fibra bruta, teores de mineral (Na e K) da farinha da folha de cenoura e do biscoito enriquecido. A fim de avaliar a aceitabilidade do produto alimentício proposto foi feita uma análise sensorial do biscoito elaborado. Nas analises físico químicas da farinha da folha de cenoura foram obtidos valores de 8,13\%, 13,77\%, 12\%, 15,85\%, 2,36\%, e 55,65\% para umidade, cinzas, fibras, proteínas, lipídeos e carboidratos, respectivamente. Com exceção ao teor de cinzas os demais parâmetros físico-químicos avaliados estão de acordo com a Legislação Brasileira relacionada a qualidade de farinhas. O biscoito enriquecido apresentou valores de 2,37\%, 1,33\%, 10\%, 9,2\%, 15,93\% e 61,17\% para umidade, cinzas, fibras, proteínas, lipídeos e carboidratos, as análises de minerais, foram encontrados os valores de $50 \mathrm{mg} / 100 \mathrm{~g}$ para o $\mathrm{Na}$ e $2240 \mathrm{mg} / 100 \mathrm{~g}$ de K. Nas análises sensoriais foi demonstrada por escala hedônica de nove pontos uma boa aceitabilidade do produto. Estes resultados indicam que a farinha da folha de cenoura pode ser uma alternativa para o enriquecimento nutricional de alimentos como o biscoito.
\end{abstract}

Palavras-chave: cenoura, análise físico-química, alimento.

\section{Introdução}

Com o aumento da população mundial e com o não crescimento paralelo de aportes alimentícios, a carência de alimentos é constante, frequentemente acarreta doenças e é responsável por grande parte da taxa de mortalidade infantil. Há uma urgente necessidade do desenvolvimento de novas fontes de nutrientes e o total aproveitamento de muitos alimentos pouco utilizados e descartados, que poderão amenizar muitas carências nutricionais. Apesar de o Brasil possuir um grande potencial agropecuário, a população vive com baixos salários, consequentemente com uma alimentação deficiente ou de baixa qualidade nutritiva (PINTO et al., 2000). Além dessa contribuição, sabe-se que várias folhas, geralmente não incluídas na dieta habitual, são consideradas 
excelentes fontes de fibras dietéticas utilizadas na prevenção de doenças cardiovasculares e gastrointestinais (ESPÍNDOLA, 1987).

A utilização de alimentos alternativos para o combate à fome na população de baixa renda é assunto que tem recebido atenção no Brasil nos últimos anos, especialmente em razão do drama crescente da população carente. Diante do quadro social e econômico da população brasileira, o estudo da utilização integral de hortaliças no uso doméstico, bem como sua incorporação na elaboração de produtos industrializados, pode contribuir substancialmente para aumentar a disponibilidade de nutrientes, sendo uma fonte de baixo custo de proteínas, fibras, vitaminas e minerais.

As folhas de cenoura são pouco utilizadas na alimentação habitual, porém a mesma pode ser uma boa fonte de fibras, vitamina B1, vitamina B2, vitamina B6, vitamina C, vitamina $\mathrm{K}$, biotina, potássio e tiamina.

Os métodos sensoriais subjetivos avaliam o quanto uma população gostou de um produto, avaliando a sua aceitabilidade. Esta pode ser dimensionada pelo grau de gostar para um produto. Um determinado alimento possui uma composição química e física particular, que gera características sensoriais percebidas pelo indivíduo, como aparência, gosto, aroma e textura. O aspecto nutricional apresenta efeitos fisiológicos após a ingestão, e influencia na seleção de um alimento, tais como a intolerância a um constituinte especifica, alergias e doenças. A escala hedônica de nove pontos tem sido utilizada com uma gama enorme de produtos alimentícios e com considerável êxito para estudos sensoriais de preferências com indivíduos adultos (DUTCOSKY, 2011; ADOLFO LUTZ, 2008)

Ante ao exposto o objetivo deste trabalho foi a determinação de parâmetros físico-químicos na farinha da folha de cenoura (Daucus carota) e a elaboração de um biscoito a base da mesma, bem como um teste de aceitabilidade do produto elaborado e a comparação dos resultados obtidos com a Legislação Vigente e outros trabalhos descritos na literatura

\section{Material e métodos}

As amostras foram coletadas no mercado municipal em Cuiabá- MT no período de 09 a 13 de janeiro de 2012, e após coleta foram higienizadas por meio de lavagem para secagem, moagem e produção da farinha.

Processo de fabricação de folha de cenoura

Inicialmente foram retiradas todas as sujeiras presentes nas folhas, para que a mesma apresentasse mais segurança quanto à qualidade microbiológica e química. 
A produção da farinha foi realizada de acordo com a metodologia utilizada por (PEREZ, 2004), por meio da secagem das folhas de cenoura em usando estufa de secagem com circulação forçada, a temperatura de $60^{\circ} \mathrm{C}$ durante 72 horas. Após este período as folhas foram trituradas em moinho de facas e a farinha de folha de cenoura foi peneirada através de tamisação até tamanho homogêneo, o conteúdo da umidade foi reduzido a $8,13 \%$.

A farinha foi processada no laboratório de Bromatologia da Universidade de Cuiabá UNIC, embalada em sacos de polietileno escuro e armazenado em temperatura ambiente.

\section{Fabricação dos biscoitos com farinha de cenoura}

A elaboração dos biscoitos enriquecidos com a farinha de folha de cenoura foi desenvolvida no Laboratório de Bromatologia da Universidade de Cuiabá - UNIC e produzidos de forma caseira, elaborados a partir de uma formulação com $10 \%$ de farinha de folha de cenoura em substituição a mesma quantidade de farinha de trigo, além da adição de açúcar refinado e manteiga a fim de melhorar a plasticidade da massa.

\section{Parâmetros físico-químicos}

O teor de cinzas foi determinado por meio do resíduo de incineração obtido por aquecimento em forno mufla em temperatura próxima a 550 a $570{ }^{\circ} \mathrm{C}$. A umidade foi determinada por meio da secagem à pressão atmosférica. Os glicídios totais em glicose foram quantificados por meio do método de Fehling modificado. O teor de proteínas foi determinado por meio do método de Kjeldahl modificado. A determinação de lipídeos foi feita por meio da extração direta em Soxhlet. O teor de fibra bruta foi determinado por meio extração em Soxhlet usando éter como solvente e posterior lavagem ácida. Todos estes parâmetros foram feitos em triplicata e acompanhados de um branco analítico, seguindo as recomendações do livro "Métodos físico-químicos para análise de alimentos" do Instituto Adolfo Lutz ( ADOLFO LUTZ, 2008).

Para a determinação da concentração de sódio e potássio, inicialmente foi construída uma curva analítica com intervalo de concentração de 0,0 a $30 \mathrm{mg} \mathrm{L}^{-1}$ de $\mathrm{Na}$ e $\mathrm{K}$ a partir de diluições sucessivas de um padrão estoque de $1000 \mathrm{mg} \mathrm{L}^{-1}$. Todas as leituras dos padrões foram feitas em triplicata e acompanhadas de um branco analítico (água destilada) em um fotômetro de chama. Em seguida, o procedimento de preparo de amostras para a determinação de Na e K consistiu na medida de massa de 0,5 g da amostra que após incineração (cinzas) em forno mufla foram transferidas para um balão volumétrico de $100 \mathrm{~mL}$, e em seguida, o volume do balão volumétrico foi completado com água destilada. Todas as leituras das amostras foram feitas em triplicata e acompanhadas de um branco analítico (água destilada). 


\section{Análise sensorial}

A aceitabilidade do produto foi avaliada por meio da escala estruturada de 9 pontos, ancorados nos extremos 1 (desgostei extremamente) e 9 (gostei extremamente) em uma equipe de 35 julgadores não treinados, recrutados entre uma população em geral (JONES et.al., 1955).

\section{Resultados e discussão}

A Tabela 1 apresenta uma comparação dos resultados obtidos na caracterização físico química da farinha da folha de cenoura deste trabalho com a farinha da cenoura descrita em trabalho por PEREIRA, 2003.

TABELA 1- Comparação dos resultados obtidos (valor médio e desvio padrão) na caracterização físico-química da farinha da folha de cenoura deste trabalho e da farinha da folha de cenoura elaborada por PEREIRA, 2003

\begin{tabular}{ccc}
\hline PARÂAETROS & $\begin{array}{c}\text { Farinha da folha de cenoura } \\
\text { elaborada neste trabalho }\end{array}$ & $\begin{array}{c}\text { Farinha folha de cenoura elaborada } \\
\text { por PEREIRA, 2003 }\end{array}$ \\
\hline Umidade (\%) & $8,13(0,05)$ & $7,20(0,07)$ \\
Cinzas (\%) & $13,77(0,25)$ & $10,50(0,33)$ \\
Lipídeos (\%) & $2,36(0,15)$ & $2,50(0,12)$ \\
Proteínas (\%) & $15,85(0,50)$ & $15,12(0,52)$ \\
Fibras Bruta (\%) & $12,00(0,18)$ & $12,00(0,26)$ \\
Carboidratos (\%) & $55,65(0,55)$ & $52,65(0,67)$ \\
Na (mg/100g) & $50,00(0,20)$ & $32,80(0,65)$ \\
K(mg/100g) & $2240(0,10)$ & $2744(4,90)$ \\
\hline
\end{tabular}

A farinha da folha de cenoura obtida neste trabalho apresentou teor de umidade de $8,13 \%$, valor situado dentro dos teores de umidade para farinhas especificadas pela ANVISA que variam de 8 a $15 \%$ e concordantes com os valores encontrados por PEREIRA, 2003. Em relação ao teor de proteínas, a farinha de folha de cenoura apresentou o valor de $15,85 \%$, valor próximo ao encontrado por PEREIRA, 2003 que é de 15,12\% resultado dentro dos parâmetros das farinhas apresentadas na legislação da CNNPA - ANVISA (BRASIL, 1978) que variam de 1,3 a 47\%.

Em relação ao resíduo mineral (cinzas), obteve-se o valor de 13,77\% concordante com o valor de 10,5\% obtido por PEREIRA, 2003, porém ambos os resultados estão fora dos parâmetros das farinhas apresentadas pela CNNPA - ANVISA (BRASIL, 1978) que variam de 1 a 6\%. Nas análises de fibras foram encontrados valores de $12 \%$ de fibra bruta, resultado idêntico ao valor encontrado por PEREIRA, 2003. Comparando os valores encontrados com outros alimentos considerados fontes de fibra como milho integral $(3,0 \%)$, cenoura $(6,0 \%)$, repolho $(8,0$, farelo de trigo integral $(11,0 \%)$, aveia integral e farelo de arroz $(13,0 \%)$, a farinha da folha de cenoura pode ser considerada uma boa alternativa de fonte de fibras. Segundo o regulamento técnico referente à informação nutricional complementar (BRASIL, 1978), o alimento sólido pode ser considerado como fonte de fibra alimentar quando apresentar $3 \mathrm{~g} / 100 \mathrm{~g}$ de amostra. 
O teor médio de carboidratos (extrato não nitrogenado) encontrado nas folhas de cenoura analisadas foi de 55,65\% b.s. valor parecido com o encontrado por (PEREIRA, 2003), que foi de $52,65 \%$ o que corresponde a $10,5 \%$ na matéria integral, podendo-se, assim, classificar as folhas de cenoura como um vegetal do tipo B por possuírem cerca de $10 \%$ de glicídios totais, segundo a classificação proposta por ORNELLAS (1979).

O valor do extrato etéreo (Lipídeos) encontrado foi de 2,36\% valor semelhante ao encontrado por (PEREIRA, 2003). Vale salientar que os resultados deste parâmetro podem variar devido a diferenças varietais, condições climáticas de cultivo e época da colheita.

O teor de $\mathrm{Na}$ encontrado nas folhas de cenoura foi de 50,00 mg / $100 \mathrm{~g}$, valor acima do encontrado por (PEREIRA,2003). Esse resultado encontra-se elevado em relação aos teores de algumas hortaliças de consumo habitual, como agrião (33,2 mg /100 g), alface (34 mg /100 g), couve-flor (34 mg / 100 g) e vagem (34,1 mg/100 g), segundo FRANCO (2000). O Na é importante na transmissão dos impulsos nervosos, mantém a pressão sanguínea, além de atuar nos sistemas de transporte de aminoácidos, glicose e diversos íons através das membranas (BRODY, 1994). O teor de potássio (K) encontrado foi de $2240 \mathrm{mg} / 100 \mathrm{~g}$, próximo ao encontrado por (PEREIRA,2003). A determinação dos íons sódio $\left(\mathrm{Na}^{+}\right)$e potássio $\left(\mathrm{K}^{+}\right)$são de extrema importância e, em alguns países, a sua declaração no rótulo de alimentos é obrigatória, devido à influência que ambos exercem sobre o controle da pressão arterial. Pessoas com tendência à hipertensão devem privilegiar alimentos com maior teor de $\mathrm{K}^{+}$e menor teor de $\mathrm{Na}^{+}$.

Os resultados obtidos nas determinações dos parâmetros físico-químicos dos biscoitos elaborados com a farinha da folha de cenoura foram comparados com os valores permitidos pela Legislação (BRASIL, 1978) e também com o biscoito obtido através de farinha de trigo e beringela descrito por PEREZ, 2004 (Tabela 2).

De acordo com a Legislação, o teor de cinzas e umidades estão em conformidade com o padrão estipulado que é de no máximo 3,0 e 14\% (m/m), respectivamente. Para os lipídeos, o valor encontrado no biscoito com a adição da farinha de cenoura foi $15,93 \%$, valor aumentado em relação a farinha de cenoura pura devido a adição de gordura vegetal, a fim de se conferir plasticidade à massa do biscoito.

Os teores de cinzas e proteínas estão próximos aos valores encontrados por (PEREZ,2004). Porém, o teor de fibras do biscoito enriquecido com farinha de cenoura é maior do que o descrito por PEREZ, 2004, o que torna o biscoito elaborado neste trabalho uma maior fonte deste importante elemento para a dieta humana. Além disso, os biscoitos podem ser considerados segundo a ANVISA (1998), como produtos prontos para o consumo, com alto teor de fibras com $10 \%$ de fibras brutas. No caso dos lipídeos, podemos observar que o biscoito enriquecido com farinha de 
cenoura possui um menor teor do mesmo quando comparado com o outro biscoito avaliado, o que também o torna mais satisfatório em termos da presença de gorduras.

TABELA 2- Comparação dos resultados obtidos no biscoito com adição de farinha da folha de cenoura e o biscoito formulado por PEREZ, 2004

\begin{tabular}{ccc}
\hline PARÂMETROS & $\begin{array}{c}\text { Biscoito com adição de } \\
\text { farinha da folha de } \\
\text { cenoura }\end{array}$ & $\begin{array}{c}\text { Biscoito formulado por } \\
\text { (PEREZ, 2004) }\end{array}$ \\
\hline Umidade (\%) & 2,37 & 4,62 \\
Cinzas (\%) & 1,33 & 1,88 \\
Lipídeos (\%) & 15,93 & 18,11 \\
Proteínas (\%) & 9,20 & 10,98 \\
Fibras (\%) & 10,00 & 6,72 \\
Carboidratos (\%) & 61,17 & - \\
Sódio (mg/100g) & 0,98 & - \\
Potássio (mg/100g) & 1,85 & - \\
\hline
\end{tabular}

Os resultados do teste de aceitação sensorial do biscoito com adição de farinha da folha de cenoura estão representados na Tabela 3.

TABELA 3- Resultados do teste de aceitação sensorial do biscoito com a adição de farinha da folha de cenoura

\begin{tabular}{cc}
\hline Escala hedônica & Porcentagem \\
\hline 1. Desgostei muitíssimo & - \\
2. Desgostei muito & - \\
3. Desgostei regularmente & - \\
4. Desgostei ligeiramente & - \\
5. Indiferente & - \\
6. Gostei ligeiramente & - \\
7. Gostei regularmente & $14,3 \%$ \\
8. Gostei muito & $65,7 \%$ \\
9. Gostei muitíssimo & $20 \%$ \\
\hline
\end{tabular}

Em relação à análise sensorial podemos considerar que a aceitação do produto foi muito boa tendo em vista que o mesmo foi avaliado por 14,3\% dos provadores como (gostei regularmente), $65,7 \%$ (gostei muito) e 20\% (gostei muitíssimo).

\section{Conclusão}

A produção da farinha de folha de cenoura e a elaboração de produtos alimentícios a partir da mesma podem ser consideradas viáveis em relação à boa aceitação do produto. Além disso, a farinha de folha de cenoura é uma excelente fonte de fibras, e minerais, e a maioria dos parâmetros 
analisados estão de acordo com a legislação exceto o teor de cinzas, tendo em vista a grande quantidade de minerais encontrados na folha de cenoura.

\title{
5. Agradecimentos
}

Os autores agradecem a Universidade de Cuiabá (UNIC) e ao Laboratório de Bromatologia da Universidade de Cuiabá (UNIC).

\begin{abstract}
This work aims at the determination of physicochemical parameters in flour leaves of carrot (Daucus carota) and the development of a cookie made of flour The physic-chemical characterization was made by determining the chemical composition, fiber, mineral content ( $\mathrm{Na}$ and $\mathrm{K}$ ) of leaf flour carrot and cookie enriched. In order to assess the acceptability of the proposed food product was made a sensory analysis of biscuits prepared. In physicochemical analysis of leaf flour carrot were obtained values of $8.13 \%, 13.77 \%, 12 \%, 15.85 \%, 2.36 \%$ and $55.65 \%$ for moisture, ash, fiber, protein, lipids and carbohydrates, respectively. Except for the ash content of the other physicochemical parameters are evaluated according to Brazilian legislation related quality of flour. The enriched cookies had values of $2.37 \%, 1.33 \%, 10 \%, 9.2 \%, 15.93 \%$ and $61.17 \%$ for moisture, ash, fiber, proteins, lipids and carbohydrates, the analysis of minerals were found 50mg/100 values for $\mathrm{Na}$ and $\mathrm{K} 2240 \mathrm{mg} / 100 \mathrm{~g}$. In the sensory analysis was shown by nine-point hedonic scale a good acceptance of the product. These results indicate that the leaf flour carrot may be an alternative to enrichment nutritional foods such as biscuits.
\end{abstract}

Key-words: carrot, physicochemical analysis, food.

\section{Referências}

BRASIL, Ministério da saúde. Secretaria de Vigilância Sanitária. Aprova normas técnicas especiais do estado de São Paulo,relativa a alimentos e bebidas.Resolução da Comissão Nacional de Normas e Padrões para alimentos CNNPA n.12, D.O.U. de 24 de julho de 1978. Seção 1, PT.1.

BRASIL.Ministério da Saúde. Secretaria de Vigilância Sanitária.Altera, e dá outras providências. Portaria n 27, de 13 de janeiro de 1998. Diário Oficial da União, Brasília, DF, 16 jan. 1998.Seção 1, p. 1-3. 1998.

BRODY, T. Nutritional biochemistry. California Academic, 1994.

DUTCOSKY, S. D., Análise sensorial de alimentos, 3 ed., Editora champagnat, 2011.

ESPÍNDOLA, F. S. Fracionamento dos vegetais verdes e obtenção de concentrados protéicos de folhas (CPF) para suplementação de alimentos e ração animal, com aproveitamento dos subprodutos. 1987. 140 f. Monografia (Graduação em Agronomia) - Universidade Federal de Uberlândia, Uberlândia.

FRANCO, G. Tabela de composição química dos alimentos, 9 ed. São Paulo: Atheneu, 2000.

INSTITUTO ADOLFO LUTZ, Métodos físico-químicos para análise de alimentos, Instituto Adolfo Lutz, Agência de Vigilância Sanitária, Ministério da Saúde, 2008.

JONES, L.V.; THURSTONE, L. L. The psychophysics of semantics: An experimental investigation. Journal of Applied Psychology., v. 39, p. 31-36, 1955. http://dx.doi.org/10.1037/h0042184

PEREZ, P. M. P. Farinha mista de trigo e berinjela: características físicas e químicas. Boletim do Centro de Pesquisa e Processamento de Alimentos ,v. 22, n. 1, p. 15-24, 2004.

PEREIRA, G. I. S.; PEREIRA, R. G. F. A.; BARCELOS, M. F. P.; MORAIS, A. R. Avaliação química da folha de cenoura visando ao seu aproveitamento na alimentação humana. Ciência e Agrotecnologia, v. 27, n. 4, 2003. http://dx.doi.org/10.1590/S1413-70542003000400017 
PINTO, N. A. V. D.; CARVALHO, V. D. ; BOTELHO, V. A. V. Determination del potencial de fibras dieteticas en las hojas de taioba (Xanthosoma sagittifolium Schott). Revista alimentaria, v. 5, n. 312, p. 87 - 90, 2000.

ORNELLAS, L. H. Técnica dietética: seleção e preparo de alimentos. 3. ed. Rio de Janeiro: Interamericana, 1979. 319 p.

Submetido em 27 jun. 2012; Redução do número de palavras por sugestão do revisor, Aceito para publicação em 15 jul. 2013. 